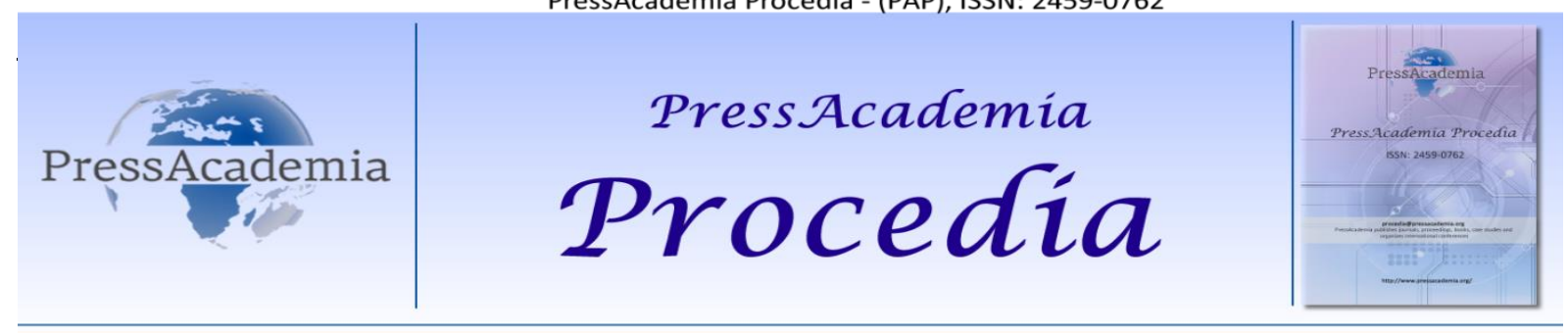

Global Business Research Congress (GBRC), May 24-25, 2017, Istanbul, Turkey.

\title{
A RESEARCH OVER PUBLISHED MASTER THESIS IN TURKEY IN BETWEEN 2010-2016 IN ACCOUNTING AND FINANCE FIELDS
}

\author{
DOI: 10.17261/Pressacademia.2017.412 \\ PAP-GBRC-V.3-2017(27)-p.269-280 \\ Zeynep Turan ${ }^{1}$, Yagmur Celik ${ }^{2}$ \\ ${ }^{1}$ Manisa Celal Bayar Üniversitesi, zeyturan92@gmail.com \\ 2 Manisa Celal Bayar Üniversitesi, yagmurrcelikk@gmail.com
}

To cite this document

Turan, Z. and Y. Celik, (2017). A research over published master thesis in Turkey in between 2010-2016 in accounting. PressAcademia Procedia (PAP), V.3, p.257-268.

Permemant link to this document: http://doi.org/10.17261/Pressacademia.2017.411

Copyright: Published by PressAcademia and limited licenced re-use rights only.

\begin{abstract}
Master thesis which provides different perspectives in terms of researches and not only enhances information production but also help raise future scholars, are as important as universities in that they supply with great applications, points of view and methods which makes them very beneficial. In this research, 990 master and PhD thesis made between 2010-2016 regarding accountantship and finance in our country, which are accessible are taken into account. In this research, content analysis method was applied taking following things into account such as the years they were made, their topics, insights they provide, methods they use and solutions they propose and meaningful results are gathered. As the data collection tool, higher education institutions' national thesis center was used.
\end{abstract}

Keywords: Accounting, finance, master thesis, doctorate thesis, content analysis method.

JEL Codes: M40, G00, 121.

\section{TÜRKIYE'DE 2010-2016 YILLARI ARASINDA MUHASEBE-FINANSMAN BiLIM DALI ÇERÇEVESINDE YAYIMLANMIŞ LISANSÜSTÜ TEZLER ÜZERINE BIR ARAŞTIRMA}

\section{ÖZET}

Hem geleceğin akademisyenlerinin yetiştirilmesine olanak sağlayan hem de bilgi üretimine katkı sağlayarak üniversitelere araştırma açısından çeşitli perspektifler sunan lisansüstü tezler; üniversiteler kadar bilim dünyasına kazandırdığı çeşitli uygulama, bakış açıları ve yöntemler bakımından oldukça faydalı birer yayın türüdür. Bu çalışmada ülkemizdeki üniversitelerde muhasebe ve finansman bilim dalı çerçevesinde 2010-2016 yılları arasında yapılmış erişime açık olan 990 yüksek lisans ve doktora tezi ele alınmıştır. Çalışma, bu tezlerin hem kendi içerisinde hem de kıstas alınan yıllar içerisinde; konuları, ilgili bilim dalına kattıkları bakış açıları, uygulama sürecinde kullanılan yöntemleri ve sunduğu çözüm önerileri göz önünde bulundurularak içerik analizi yöntemi uygulanmış ve anlamlı sonuçlar elde edilmiştir. Veri toplama aracı olarak Yükseköğretim Kurumu Ulusal Tez Merkezi kullanılmıştır.

Anahtar Kelimeler: Muhasebe, Finans, Yüksek Lisans tezleri, Doktora tezleri, İçerik analizi yöntemi. Jel Sınıflandırması: M40, G00, I21. 


\section{GíRiş}

Üniversitelerin misyonu, ilgi alanlarını belirleyen ve onların üzerine yoğunlaşan, bilgiyi dinleyerek değil araştırarak ve sorgulayarak edinen, kendi bilgilerini toplum ve ülke yararına kullanmayı amaç edinmiş, perspektifi geniş insanlar yetiştirmektir. Bu bağlamda lisansüstü eğitimler oldukça önem kazanan ve yeri geniş bir alana sahiptir. Lisansüstü eğitim aşamasında bireylerin, artık bilgisini sentezleme aşamasına geçmiş, bildiği ile yetinmeyen ve yeniyi üreten bir konuma gelmesi beklenmektedir. Bu amaçla lisansüstü eğitimin tamamlanması ile ortaya konan lisansüstü tezler, akademik bilgi üretimine katkı sağlayan, bilgi kullanıcıların hem bakış açılarını geliştirmeyi hem de kanıtlanmış bilgiyi elde etmelerine olanak sağlayan, en önemlisi ilgili alanların uzman kişilerini ve geleceğin akademisyenlerini yetiştirmeyi hedefleyen bir niteliğe sahiptir. Bu sayede yazarlar, seçtikleri konu ışı̆̆ında geleceklerindeki çalışma alanlarını şekillendirme imkanına sahip olurlar.

Lisansüstü tezler, literatüre sağladığı katkı açısından oldukça önemli verilerdir. Çünkü her bir tez çalışması, yazıldığı bilim dalına mutlak suretle üretilmiş bir bilimsel bilgi sunmaktadır. Bir bilim dalında ne kadar çok tez yazıldıysa, o bilim dalında o denli çeşitlilik var demektir. Böylece sunulan bilgiler daha derinlemesine, daha doğruluğu kanıtlanmış, üzerinde çalışılmış ve mutlaka üzerine yoğunlaşılmış bir anakütleden seçilen örneklem üzerinde denenerek doğruluğu kanıtlanmış bir nitelik kazanmaktadır. Lisansüstü tezler, gelecekte ilgili yazarların adeta akademik bir kimliği olacağından, yazarlar tarafından tezlerin içeriği hazırlanırken mutlaka verilerin belirli analizlerden geçerek doğruluğu kanıtlanmış olması ve gerçeğe en yakın bilgiyi sunarak gelecekte benzer bilgilere ihtiyaç duyması muhtemel bilgi kullanıcılarına yol göstermesi gerekmektedir.

Lisansüstü tezler gibi bilimsel tüm araştırmalarda kullanılan analiz yöntemlerinden biri olan bibliyometrik analizler, analiz edilecek konu ile ilgili toplanan yayımların spesifik özelliklerinin incelenmesiyle elde edilen verileri incelemektedir. Böylece incelenen kişi yada kurumların ne derece verimli olduğu görülmekle birlikte bibliyometrik analizin temel amacı, saptanan konu ile ilgili yayımlanmış yayınların sayıca fazlalığına paralel olarak o konunun popülaritesinin ölçülmesidir. Bir diğer analiz yöntemi olan içerik analizi yöntemi ise bibliyometrik analize kıyasla nitel verileri incelemekle birlikte, analiz yapılacak konu ile ilgili nitel verilerin toplanarak yorumlanma sürecinde nicel verilere dönüştürülerek anlamlı sonuçlara ulaşma yolu olarak tanımlanabilmektedir.

Bu çalışmada yukarıda açıklanan düşüncelerden hareketle, Türkiye'de son altı yılda muhasebe ve finansman üzerine yazılmış yüksek lisans ve doktora tezleri, bibliyometrik analiz ve içerik analizi yöntemleri ile incelenmek suretiyle ele alınmış ve hem güncel hem de anlamlı sonuçlara ulaşıımıştır. Bu çalışmanın öncelikli amacı, ilgili bilim dallarında lisansüstü çalışmalar yapan öğrencilere ve onlara önderlik eden akademisyenlere ışı tutmak, bilim dalları üzerinde yoğunlaşılan konuları ve nispeten üzerinde daha az çalışılan alanları belirleyerek bilgi kullanıcılarının ilgi alanlarını daha faydalı ve objektif bir biçimde belirlemesine yardımcı olmaktır. Böylece muhasebe ve finansman bilim dallarında gerek henüz açıklığa kavuşmamış, gerek ise üzerinde derinlemesine çalışılmamış, bir diğer deyişle göz ardı edilmiş alanları ön plana çıkması mümkün olacak, lisansüstü çalışma yapan bireylerin belirli alanlara yığılmaların oluşması engellenebilecek, sonucunda çalışma yapan öğrencilere de alanında farklılaşma imkanı doğacaktır.

\section{LITERATÜR TARAMASI}

Lisansüstü tezler ile ilgili çeşitli değerlendirmeler yapılmıştır. Özellikle bibliyometrik analizler tercih edilmekle birlikte tezlerin içerik analizleri, konulara göre kategorize etme, atıflarda bulunma, veri toplama teknikleri gibi çeşitli yöntemlerle lisans üstü tezler incelenmiştir. Tezlerde ele alınan konular, o bilim dalındaki bilgi birikiminin kapsamına ilişkin önemli sonuçlar ortaya koymaktadır.

Armutlu ve Arı (2010), işletme bilim dalı başlığı altında; toplam kalite yönetimi, kalite çemberleri, değişim mühendisliği, altı sigma, kıyaslama ve personel geliştirme konuları bibliyometrik analiz kullanılarak değerlendirilmiştir. Tezlerde yönetim modalarına gösterilen ilgiyi tespit etmeyi amaçlayan bir çalışma gerçekleştirilmiştir.

Yereli, Kayalı vd. (2010), uluslararası dergilerde muhasebe eğitimi konusunda, yer alan makaleler gözden geçirilerek makaleler içerik analizi yönteminden yararlanılarak konuları, veri toplama yöntemleri ve yazar sayıları gibi kıstaslara göre sınıflandırılmıştır. Yapılan bu çalışma 1997-2008 yılları arasını kapsamaktadır. 
Benligiray (2012), üniversitelerde lisansüstü düzeyde eğitim gören araştırmacıların; bankacılık konusunda önem verdikleri, pratik ve kuramsal yarar gördükleri problemlerin çözümüne odaklanan tezler yaptıkları tespit edilerek çalışmalar; içerik analizi ve ki kare analizi çerçevesinde ele alınmıştır.

Bozyiğit ve Yaşa (2012), Türkiye'deki üniversitelerde pazarlama alanında yapılmış olan lisansüstü tez çalışmaları içerik analiz yöntemi ile incelenmiştir. Yapılan çalışmada pazarlama alanındaki mevcut genel dağılımı tespit etmek amaçlanmıştır.

Alkan (2014), Türkiye'de muhasebe alanında yapılan lisansüstü tez çalışmalarını içerik analiz yöntemini kullanarak bu çalışmaların gerek konuları gerekse alana katkıları, değerlendirmeler sonucunda geliştirilen önerileri gibi kriterlere göre sınıflandırıp incelemiştir. Yaptığı bu çalışma 1984-2012 yılları arasını kapsamaktadır.

Elitaş (2016), Türkiye'deki muhasebe tarihi çalışmaları nicel bir araştırma yöntemi olan meta-analiz ile incelenmiştir. Bu çalışma 2005-2015 yılları arasındaki yerli bilimsel çalışmaları kapsamaktadır.

Güngörmüş (2016), Türkiye'de muhasebe standartlarına yönelik yazılan yüksek lisans ve doktora tezleri içerik analiz yöntemi kullanılarak değerlendirilerek en çok yazılan standartlar ile yeteri kadar araştırma yapılmamış standartlar tespit edilmiştir. Bu alanda araştırma yapmayı düşünen öğrencileri ve akademisyenleri bilgilendirmek amaçlanmıştır.

Solmaz ve Gökçearslan tarafından yapılan çalışmada (2016), Türkiye'de mobil öğrenme alanı ile ilgili yapılmış yüksek lisans ve doktora çalışmaları; tez yılı, tez türü , anabilim dalı, yöntem, veri toplama araçları gibi değişkenler açısından incelenerek, içerik analizi yapılmıştır. Araştırma 2005-2015 yılları arasını kapsamakla beraber 48 çalışma incelenmiştir.

Tekin (2016), Türkiye'de turizm ile ilgili anabilim dallarında hazırlanmış ve yayımlanmış tüm tezler incelenip bu tezlerde odaklanılan konular içerik analiz yöntemi ile tespit edilmiştir. Bu çalışma 1985-2004 yılları arasını kapsamaktadır.

Akyüz ve Yeşil (2017), Türkiye Finansal Raporlama Standartları açısından muhasebe meslek mensuplarına yönelik yapılan akademik çalışmalar incelenmekle birlikte muhasebe meslek mensuplarının muhasebe standartlarıyla ilgili beklentileri ve bilgi düzeyleri ölçülmüştür.

\section{VERI VE YÖNTEM}

\subsection{Araştırmanın Amacı ve Önemi}

Üniversitelerin adeta bir bilimsel bilgi üretme merkezi olduğu herkes tarafından bilinen bir gerçektir. Kuşkusuz bu bilgi üretme işlevini yerine getiren en önemli araçlardan bir tanesi de lisansüstü tez çalışmalarıdır. Lisansüstü tez çalışmaları, alanında bilgi sahibi öğrenciler ve onlara ışık tutan profesyonel akademisyenlerin işbirliği ile ortaya aktarılabilir ve doğruluğu kanıtlanmış bilimsel bilgiler sunarlar. Çalışılan her alanda olduğu gibi muhasebe ve finansman alanlarında yapılan lisansüstü çalışmaların da ürettiği bilimsel bilgiler ve yeni teknolojiler açısından literatüre katkısı oldukça önemlidir.

Bu çalışmanın amacı, ülkemizde muhasebe ve finansman alanlarında son altı yılda yapılmış lisansüstü çalışmaların kendi içerisindeki alan dağılımlarının incelenerek öncelikle hangi alanlarda ne kadar çalışma yapılmış olduğunu ortaya koymaktır. Bununla birlikte bu çalışma, lisansüstü çalışmalar yapacak öğrencilerin alanında yapılmış çalışmaları incelemesi sağlanarak onların daha yaratıcı olmaları ve çalışma alanlarına daha çok bilimsel katkı sağlamaları amaçlanmaktadır. Böylece belirli ilgi çekici konulara yığılmaların olması ve aynı konuda birbirine benzer çalışmaların yapılması ortadan kalkması mümkün olabilecektir. Yapılan çalışma, günümüz lisansüstü öğrencilerinin ve bu alanda çalışmaya aday bilgi kullanıcılarının, alan içerisindeki güncel dağılımları görerek kendi gerek ilgi alanlarını belirlemek, gerek ise hem kendi geleceklerine hem de literatüre daha fazla katkıda bulunmalarını sağlayabilmek açısından önemli bir çalışmadır.

\subsection{Araştırmanın Yöntemi}

Yapılan çalışmada olduğu gibi, nitel veri analizi yaparak bilimsel veri üretme amacı taşıyan çalışmalarda, veri analiz yöntemi olarak sıklıkla içerik analizi yöntemi kullanılmaktadır. İçerik analizi yönteminde, araştırma yapılacak alan içerisinde oluşturulan bilgi havuzunda birbirine benzer olan nitel bilgilerin anahtar kelimeler liderliğinde sınıflandırılması ve bu sınıflamalar dahilinde verilerin düzenlenerek anlamlandırılması temel amaçtır (Alkan, 2012). Bu analiz yöntemi sayesinde elde edilen bilgiler arasında çok daha kolay ilişki kurulabilmekte ve ihtiyaç sahibi bilgi kullanıcılarına daha anlamlı sonuçlar ulaştırılabilmektedir.

Bu çalışmada, son altı yılda muhasebe ve finansman alanlarında yapıımış lisansüstü çalışmalara ait bilgiler Yükseköğretim Kurulu Ulusal Tez Merkezi aracılığıyla elde edilmiş, ulaşılan lisansüstü çalışmalar öncelikle çalışılmış oldukları anabilim ve bilim dalları çerçevesinde sınıflara ayrılmış, elde edilen çalışmalar yazarı, yapıldığı üniversite, yayım yılı, çalışma türü ve ait olduğu alan baz alınarak Excel programı üzerinde sınıflandırılmış ve elde edilen veriler arası anlamlı ilişkiler kurularak analiz gerçekleştirilmiştir.

\subsection{Araştırmanın Kapsamı ve Sınırlılıkları}


Bu araştırmada veri tabanı olarak, veri tabanına kayıtlı olan tezlerin muhasebe ve finansman alanlarına hitapeden bütün tezleri kapsadığı ve bu tezlerin kurum tarafından elektronik veri tabanına doğru ve güvenilir bir şekilde kaydedildiği temel varsayımıyla, Yükseköğretim Kurulu (YÖK) Ulusal Tez Merkezi kullanılmıştır.

YÖK Ulusal Tez Merkezi'nden yapılan detaylı tarama sonucunda araştırma kapsamına, Muhasebe Denetimi Anabilim Dalı, Muhasebe ve Finansal Yönetim Anabilim Dalı ile Muhasebe ve Finansman Anabilim Dalı ile İşletme Anabilim Dalı'na ait olan Muhasebe Bilim Dalı, Muhasebe ve Denetim Bilim Dalı, Muhasebe ve Denetimi Bilim Dalı, Muhasebe ve Finansman Bilim Dalı dahil edilmiş, sonucunda 1210 adet tez bulunmuştur. Bunların 1062'i yüksek lisans, 148 'i ise doktora tezidir. Ele alınan tezlerin 164'ü yüksek lisans, 56'sı doktora olmak üzere toplamda 220'si izinsiz olduğundan araştırma kapsamına dahil edilmemiş, araştırma kapsamında 818 yüksek lisans tezi ve 172 doktora tezi olmak üzere 990 adet tez incelenmiştir.

\section{BULGULAR VE TARTIŞMA}

Yapılan çalışmada veri tabanı olarak kullanılan YÖK Ulusal Tez Merkezi'nden edinilen verilere göre, ülkemizde 2010-2016 yılları arasında muhasebe ve finansman alanlarına hizmet eden ve erişim izni olan 990 lisansüstü çalışma bulunmaktadır. Yapılan bu çalışmaların 818'i yüksek lisans, 172 'si ise doktora tezidir.

Tablo 1: Muhasebe-Finansman Alanındaki Tezlerin Yıllara Göre Dağılımı

\begin{tabular}{cccccc}
\hline YILLAR / GENEL TOPLAM & MUHASEBE & FINANSMAN & TOPLAM & YÜZDE (MUHASEBE) & YÜZDE (FiNANSMAN) \\
\hline $\mathbf{2 0 1 0}$ & 151 & 103 & 254 & $\% 59.5$ & $\% 40.5$ \\
$\mathbf{2 0 1 1}$ & 83 & 39 & 122 & $\% 68.1$ & $\% 31.9$ \\
$\mathbf{2 0 1 2}$ & 82 & 46 & 128 & $\% 64.1$ & $\% 35.9$ \\
$\mathbf{2 0 1 3}$ & 90 & 43 & 133 & $\% 67.7$ & $\% 32.3$ \\
$\mathbf{2 0 1 4}$ & 85 & 34 & 120 & $\% 70.9$ & $\% 29.1$ \\
$\mathbf{2 0 1 5}$ & 105 & 33 & 138 & $\% 76.1$ & $\% 23.9$ \\
$\mathbf{2 0 1 6}$ & 74 & 21 & 95 & $\% 77.9$ & $\% 22.1$ \\
\hline TOPLAM & $\mathbf{6 7 0}$ & $\mathbf{3 2 0}$ & $\mathbf{9 9 0}$ & $\% 67.67$ & $\% 32.33$ \\
\hline
\end{tabular}

Araştırma kapsamına alınan 990 adet lisansüstü çalışmanın baz alınan yıllar ve hizmet ettiği alanlara ait bilgileri, Tablo.1'de verilmiştir. Son altı yılda muhasebe ve finansman alanlarında yapılan lisansüstü çalışmalarının yaklaşık \%68'i muhasebe, geri kalan \%32'si ise finansman alanına hizmet etmektedir. Bununla birlikte bu alanda yapılan çalışmaların 2010 yılı itibariyle yavaş yavaş azalan bir profil çizdiği de görünen bir gerçektir.

Tablo 2: Muhasebe-Finansman Alanında Yazılan Yüksek Lisans Tezlerinin Yıllara Göre Dağılımı

\begin{tabular}{cccccc}
\hline YILLAR / TOPLAM & MUHASEBE & FINANSMAN & TOPLAM & YÜZDE (MUHASEBE) & YÜZDE (FiNANSMAN) \\
\hline $\mathbf{2 0 1 0}$ & 121 & 88 & $\mathbf{2 0 9}$ & $\% 57.9$ & $\% 42.1$ \\
$\mathbf{2 0 1 1}$ & 69 & 27 & $\mathbf{9 6}$ & $\% 71.9$ & $\% 28.1$ \\
$\mathbf{2 0 1 2}$ & 57 & 36 & $\mathbf{9 3}$ & $\% 61.3$ & $\% 38.7$ \\
$\mathbf{2 0 1 3}$ & 78 & 27 & $\mathbf{1 0 5}$ & $\% 74.3$ & $\% 25.7$ \\
$\mathbf{2 0 1 4}$ & 78 & 23 & $\mathbf{1 0 1}$ & $\% 77.2$ & $\% 22.8$ \\
$\mathbf{2 0 1 5}$ & 100 & 27 & $\mathbf{1 2 7}$ & $\% 78.8$ & $\% 21.2$ \\
$\mathbf{2 0 1 6}$ & 69 & 18 & $\mathbf{8 7}$ & $\% 79.3$ & $\% 20.6$ \\
TOPLAM & $\mathbf{5 7 2}$ & $\mathbf{2 4 6}$ & $\mathbf{8 1 8}$ & $\mathbf{\% 6 9 . 9 2}$ & $\% 30.07$ \\
\hline
\end{tabular}

Tablo.1 verilerinin daha spesifik hale getirilmesi açısından, son altı yılda yapıımış olan yüksek lisans çalışmaları, baz alınan yıllar ve ait olduğu alan açısından Tablo.2'de incelenmiştir. Muhasebe ve finansman alanında oluşturulmuş yüksek lisans tezlerinin \%70'inin muhasebe, \%30'unun ise finans alanına ait olduğu, böylece yüksek lisans öğrencilerinin genel ilgi alanının finans alanından çok muhasebe alanı olduğu görülmüştür.

Tablo3: Muhasebe-Finansman Alanında Yazılan Doktora Tezlerinin Yıllara Göre Dağııımı 


\begin{tabular}{cccccc}
\hline YILLAR / TOPLAM & MUHASEBE & FINANSMAN & TOPLAM & YÜZDE (MUHASEBE) & YÜZDE (FINANSMAN) \\
\hline $\mathbf{2 0 1 0}$ & 30 & 15 & $\mathbf{4 5}$ & $\% 66.7$ & $\% 33.3$ \\
$\mathbf{2 0 1 1}$ & 14 & 12 & $\mathbf{2 6}$ & $\% 53.9$ & $\% 46.1$ \\
$\mathbf{2 0 1 2}$ & 25 & 10 & $\mathbf{3 5}$ & $\% 71.5$ & $\% 28.5$ \\
$\mathbf{2 0 1 3}$ & 12 & 16 & $\mathbf{2 8}$ & $\% 42.9$ & $\% 57.1$ \\
$\mathbf{2 0 1 4}$ & 7 & 12 & $\mathbf{1 9}$ & $\% 36.9$ & $\% 63.1$ \\
$\mathbf{2 0 1 5}$ & 5 & 6 & $\mathbf{1 1}$ & $\% 45.5$ & $\% 54.5$ \\
$\mathbf{2 0 1 6}$ & 5 & 3 & $\mathbf{8}$ & $\% 62.5$ & $\% 37.5$ \\
\hline TOPLAM & $\mathbf{9 8}$ & $\mathbf{7 4}$ & $\mathbf{1 7 2}$ & $\mathbf{9 5 6 . 9 7}$ & $\% 43.03$ \\
\hline
\end{tabular}

Bir diğer lisansüstü çalışma türü olan doktora çalışmaları, araştırma kapsamına alınan veriler çerçevesinde yıl ve alan bazında Tablo.3'de incelenmiş, bu alanda yapılan çalışmaların \%57'sinin muhasebe, \%43'ünün finansman alanında gerçekleştirildiği görülmüştür. Yüksek lisans çalışmaları kadar olmasa da doktora çalışmalarında da muhasebe alanının finans alanına kıyasla daha fazla tercih edildiği görülmektedir. Ancak bu alanda yapılan yüksek lisans çalışmalarına göre doktora çalışmalarında finans alanına daha fazla ilgi olduğu da söylenebilmektedir.

Çalışmanın bu bölümünde, muhasebe ve finansman alanlarında yapılmış lisansüstü çalışmaların çalışma türü sınıflandırılması yapılmış, ele alınan çalışmalar teorik ve ampirik olma özelliklerine göre incelenmiştir.

Tablo 4: Muhasebe Alanında Yapılan Lisansüstü Çalışmaların Çalışma Türü Sınıflandırması

\begin{tabular}{|c|c|c|c|}
\hline ÇALIŞMALAR - MUHASEBE & YÜKSEK LISANS & DOKTORA & TOPLAM \\
\hline Teorik Çalışmalar & 318 & 10 & $\mathbf{3 2 8}$ \\
\hline Ampirik Çalışmalar & 254 & 88 & $\mathbf{3 4 2}$ \\
\hline TOPLAM & $\mathbf{5 7 2}$ & $\mathbf{9 8}$ & $\mathbf{6 7 0}$ \\
\hline
\end{tabular}

Tablo.4'te, muhasebe alanında yapılmış lisansüstü çalışmaların çalışma türü sınıflandırması, yüksek lisans ve doktora olmak üzere gerçekleştirilmiş ve muhasebe alanında son altı yılda 670 adet çalışma yapılmış, bu çalışmaların \%49'unun teorik, \%51'inin ise ampirik çalışma olduğu saptanmıştır. Bu durumda, muhasebe alanında öğrenim gören yüksek lisans öğrencilerinin teorik çalışmalar yapmaya kısmen daha yatkın olduğu, artık profesyonellik kazanma basamağı olan doktora çalışmalarında ise öğrencilerin ampirik çalışmalara önem verdiği görülmektedir.

Tablo 5: Finansman Alanında Yapılan Lisansüstü Çalışmaların Çalışma Türü Sınıflandırması

\begin{tabular}{|c|c|c|c|}
\hline ÇALIŞMALAR - FINANSMAN & YÜKSEK LISANS & DOKTORA & TOPLAM \\
\hline Teorik Çalışmalar & 98 & 148 & $\mathbf{2 4 6}$ \\
\hline Ampirik Çalışmalar & 6 & 68 & $\mathbf{7 4}$ \\
\hline TOPLAM & $\mathbf{1 0 4}$ & $\mathbf{2 1 6}$ & $\mathbf{3 2 0}$ \\
\hline
\end{tabular}

Tablo.5'de, finansman alanında yapılmış lisansüstü çalışmaların çalışma türü sınıflandırması, yüksek lisans ve doktora olmak üzere gerçekleştirilmiş ve finansman alanında \%77'si teorik, \%23'ü ampirik çalışma olmak koşuluyla son altı yılda toplamda 320 adet çalışma yapıldığı görülmüştür. Bu tablodan hareketle, muhasebe alanının aksine finansman alanında gerek yüksek lisans, gerek doktora öğrencilerinin ciddi bir teorik çalışma yatkınlığı gösterdiği açıkça görülmektedir.

Çalışmanın bu kısmında, ele alınan lisansüstü çalışmaların yapıldığı üniversiteler baz alınarak sınıflandırma yapılmış, yüksek lisans ve doktora çalışmaları olarak ayrı bir şekilde Tablo.6 ve Tablo.7'de gösterilmiştir.

Tablo 6: Muhasebe-Finansman Alanında Yazılan Yüksek Lisans Tezlerinin Üniversitelere Göre Dağılımı

\begin{tabular}{lcccc}
\hline \multicolumn{1}{c}{ ÜNIVERSITELER - YÜKSEK LISANS TEZLERI } & MUHASEBE & FINANSMAN & TOPLAM & YÜZDE \\
\hline Marmara Üniversitesi & 102 & 29 & 131 & 0,16 \\
Okan Üniversitesi & 124 & 6 & 130 & 0,16 \\
Gazi Üniversitesi & 31 & 32 & 63 & 0,08 \\
\hline
\end{tabular}




\begin{tabular}{|c|c|c|c|c|}
\hline Istanbul Ticaret Üniversitesi & 52 & 2 & 54 & 0,07 \\
\hline Niğde Üniversitesi & 20 & 14 & 34 & 0,04 \\
\hline Sakarya Üniversitesi & 17 & 14 & 31 & 0,04 \\
\hline Istanbul Aydın Üniversitesi & 24 & 4 & 28 & 0,03 \\
\hline Selçuk Üniversitesi & 13 & 14 & 27 & 0,03 \\
\hline Dokuz Eylül Üniversitesi & 23 & 4 & 27 & 0,03 \\
\hline Manisa Celal Bayar Üniversitesi & 15 & 10 & 25 & 0,03 \\
\hline Hacettepe Üniversitesi & 8 & 15 & 23 & 0,03 \\
\hline Süleyman Demirel Üniversitesi & 11 & 8 & 19 & 0,02 \\
\hline Başkent Üniversitesi & 13 & 6 & 19 & 0,02 \\
\hline İstanbul Üniversitesi & 17 & 1 & 18 & 0,02 \\
\hline Atatürk Üniversitesi & 5 & 12 & 17 & 0,02 \\
\hline Gaziosmanpaşa Üniversitesi & 6 & 11 & 17 & 0,02 \\
\hline Inönü Üniversitesi & 7 & 8 & 15 & 0,02 \\
\hline Cumhuriyet Üniversitesi & 9 & 4 & 13 & 0,01 \\
\hline Pamukkale Üniversitesi & 2 & 10 & 12 & 0,01 \\
\hline Uludağ Üniversitesi & 7 & 5 & 12 & 0,01 \\
\hline Erciyes Üniversitesi & 8 & 3 & 11 & 0,01 \\
\hline Kocaeli Üniversitesi & 6 & 4 & 10 & 0,01 \\
\hline Balıkesir Üniversitesi & 4 & 5 & 9 & 0,01 \\
\hline Maltepe Üniversitesi & 2 & 5 & 7 & 0,01 \\
\hline Anadolu Üniversitesi & 4 & 2 & 6 & 0,01 \\
\hline Mehmet Akif Ersoy Üniversitesi & 2 & 4 & 6 & 0,01 \\
\hline Haliç Üniversitesi & 5 & 1 & 6 & 0,01 \\
\hline Dumlupınar Üniversitesi & 4 & 2 & 6 & 0,01 \\
\hline Gaziantep Üniversitesi & 1 & 4 & 5 & 0,00 \\
\hline Işık Üniversitesi & 5 & 0 & 5 & 0,00 \\
\hline Trakya Üniversitesi & 5 & 0 & 5 & 0,00 \\
\hline Istanbul Arel Üniversitesi & 4 & 0 & 4 & 0,00 \\
\hline Karadeniz Teknik Üniversitesi & 3 & 0 & 3 & 0,00 \\
\hline Karamanoğlu Mehmet Bey Üniversitesi & 3 & 0 & 3 & 0,00 \\
\hline Bülent Ecevit Üniversitesi & 1 & 2 & 3 & 0,00 \\
\hline Adnan Menderes Üniversitesi & 1 & 1 & 2 & 0,00 \\
\hline Çanakkale On Sekiz Mart Üniversitesi & 2 & 0 & 2 & 0,00 \\
\hline Gebze Yüksek Teknoloji Enstitüsü & 0 & 2 & 2 & 0,00 \\
\hline Diğer & 6 & 2 & 8 & 0,08 \\
\hline TOPLAM & 572 & 246 & 818 & 1,00 \\
\hline
\end{tabular}

Tablo.6'dan da anlaşılacağı gibi, yüksek lisans çalışmaları açısından muhasebe-finansman alanında en çok bilimsel çalışma ürettiği görülen üniversiteler, \%16'lık bir dilime sahip olan Marmara Üniversitesi ve bu üniversite ile aynı oranı paylaşan Okan Üniversitesi ile \%8'lik bir oran ile Gazi Üniversitesi olmuştur. Tablo incelendiğinde, Marmara ve Okan Üniversiteleri'nin muhasebe alanına, Gazi Üniversitesi'nin ise ufak bir fark ile finansman alanına bilgi sağladığı görülmektedir. Bunun haricinde özellikle İstanbul Ticaret Üniversitesi, Niğde Üniversitesi ve Sakarya Üniversitesi ile İstanbul Aydın Üniversitesi, Selçuk Üniversitesi, Dokuz Eylül Üniversitesi ve Celal Bayar Üniversitesi öğrencileri de son altı yılda muhasebe-finansman alanında önemli ölçüde çalışmalar yaptığı gözlenmektedir.

Tablo 7: Muhasebe-Finansman Alanında Yazılan Doktora Tezlerinin Üniversitelere Göre Dağılımı

\begin{tabular}{lcccc}
\hline \multicolumn{1}{c}{ ÜNiVERSiTELER - DOKTORA TEZLERI } & MUHASEBE & FINANSMAN & TOPLAM & YÜZDE \\
\hline Marmara Üniversitesi & 25 & 14 & 39 & 0,23 \\
Sakarya Üniversitesi & 12 & 16 & 28 & 0,16 \\
Gazi Üniversitesi & 5 & 12 & 17 & 0,10 \\
İstanbul Üniversitesi & 15 & 1 & 16 & 0,09 \\
\hline
\end{tabular}




\begin{tabular}{|lllll}
\hline Erciyes Üniversitesi & 2 & 8 & 10 & 0,06 \\
\hline Başkent Üniversitesi & 4 & 4 & 8 & 0,05 \\
\hline Atatürk Üniversitesi & 6 & 1 & 7 & 0,04 \\
\hline Selçuk Üniversitesi & 4 & 1 & 5 & 0,03 \\
\hline Anadolu Üniversitesi & 4 & 1 & 5 & 0,03 \\
\hline Inönü Üniversitesi & 2 & 2 & 4 & 0,02 \\
\hline Kocaeli Üniversitesi & 3 & 1 & 4 & 0,02 \\
\hline Niğde Üniversitesi & 4 & 0 & 0,02 \\
\hline Süleyman Demirel Üniversitesi & 2 & 2 & 4 & 0,02 \\
\hline Ankara Üniversitesi & 1 & 2 & 3 & 0,02 \\
\hline Cumhuriyet Üniversitesi & 0 & 3 & 0,02 \\
\hline Çukurova Üniversitesi & 3 & 0 & 3 & 0,02 \\
\hline Hacettepe Üniversitesi & 0 & 3 & 0,02 \\
\hline Uludağ Üniversitesi & 3 & 3 & 3 & 0,02 \\
\hline Gaziosmanpaşa Üniversitesi & 0 & 0 & 2 & 0,01 \\
\hline Afyon Kocatepe Üniversitesi & 0 & 2 & 1 & 0,00 \\
\hline Manisa Celal Bayar Üniversitesi & 1 & 1 & 1 & 0,00 \\
\hline Dokuz Eylül Üniversitesi & 1 & 0 & 1 & 0,00 \\
\hline Gebze Yüksek Teknoloji Enstitüsü & 1 & 0 & 1 & 0,00 \\
\hline TOPLAM & $\mathbf{1 8}$ & 0 & $\mathbf{1 7 2}$ & $\mathbf{1 , 0 0}$ \\
\hline
\end{tabular}

Tablo.7, doktora düzeyinde yapılan tez çalışmaları açısından muhasebe-finansman alanına en fazla bilimsel bilgi sunduğu görülen üniversitelerin başında, yüksek lisans tezlerinde olduğu gibi \%23'lük bir oran ile Marmara Üniversitesi gelmekte ve sırayı \%16 ve \%10 oranları ile Sakarya Üniversitesi ve Gazi Üniversitesi takip etmektedir. Marmara Üniversitesi'nin aksine, Gazi Üniversitesi doktora öğrencilerinin tıpkı yüksek lisans öğrencileri gibi finansman alanına daha fazla yatkınlık gösterdiği, Sakarya Üniversitesi doktora öğrencilerinin de ağılıklı olarak finansman alanında çalıştığı gözlenmektedir. Bununla birlikte, İstanbul Üniversitesi, Erciyes Üniversitesi, Başkent Üniversitesi ve Atatürk Üniversitesi'ndeki doktora öğrencilerinin de son altı yıl içerisinde ilgili alana katkı sağladığını söylememiz mümkündür. Lisansüstü çalışmalar anlamında bütünü ele aldığımızda ise, Marmara Üniversitesi'nin \%17, Okan Üniversitesi'nin \%13, Gazi Üniversitesi'nin \%8, Sakarya Üniversitesi'nin \%6, İstanbul Ticaret Üniversitesi'nin \%5 ve İstanbul Üniversitesi'nin \%3'lük payları ile araştırma kapsamında ele alınan lisansüstü çalışmaların \%52'lik bir kısmına sahip olduğu görülmektedir.

Çalışmanın bu bölümünde, ele alınan lisansüstü tezlerin alanları dahilinde konu dağılımları incelenmiş, yığılmaların gözlemlendiği konular ayrıca ele alınarak analiz edilmiştir.

Tablo 8: Araştırma Kapsamındaki Tezlerin Konu Dağılımları

\begin{tabular}{lcccc}
\hline KONU & YÜKSEK LiSANS & DOKTORA & TOPLAM & YÜZDE \\
\hline Denetim & 142 & 25 & 167 & 0,17 \\
\hline Standartlar (UFRS-TFRS-TMS) & 129 & 25 & 154 & 0,16 \\
Finansal Uygulamalar & 111 & 15 & 126 & 0,13 \\
Maliyet Muhasebesi & 71 & 18 & 89 & 0,09 \\
Finansal Analiz & 48 & 12 & 60 & 0,06 \\
Finansal Yönetim & 20 & 13 & 33 & 0,04 \\
\hline Yönetim Muhasebesi & 21 & 11 & 32 & 0,04 \\
Muhasebe Uygulamaları & 25 & & 25 & 0,03 \\
Vergi Muhasebesi & 23 & & 23 & 0,02 \\
\hline Finansal Performans & 16 & 7 & 23 & 0,02 \\
\hline Dış Ticaret Muhasebesi & 20 & & 20 & 0,02 \\
Finans Denetimi & 16 & 2 & 18 & 0,02 \\
işletme Birleşmeleri & 12 & 2 & 14 & 0,01 \\
Türev Piyasalar & 7 & 7 & 14 & 0,01 \\
\hline Transfer Fiyatlandırması & 13 & & 13 & 0,01 \\
Muhasebe Meslek Mensupları & 10 & 3 & 13 & 0,01 \\
\hline
\end{tabular}




\begin{tabular}{|c|c|c|c|c|}
\hline Basel II & 10 & 3 & 13 & 0,01 \\
\hline Adli Muhasebe & 10 & 2 & 12 & 0,01 \\
\hline Küresel Kriz & 11 & & 11 & 0,01 \\
\hline Muhasebe Etiği & 10 & 1 & 11 & 0,01 \\
\hline Çevre Muhasebesi & 10 & 1 & 11 & 0,01 \\
\hline Genel Muhasebe & 8 & 2 & 10 & 0,01 \\
\hline Devlet Muhasebesi & 7 & 1 & 8 & 0,01 \\
\hline Şirketler Muhasebesi & 7 & 1 & 8 & 0,01 \\
\hline Finansal Araçlar & 6 & 2 & 8 & 0,01 \\
\hline Inşaat Muhasebesi & 7 & & 7 & 0,01 \\
\hline Finansal Risk Yönetimi & & 7 & 7 & 0,01 \\
\hline Muhasebe Bilgi Sistemi & 6 & & 6 & 0,01 \\
\hline Hesap Planı & 5 & & 5 & 0,01 \\
\hline Yaratıcı Muhasebe & 5 & & 5 & 0,01 \\
\hline Muhasebe Eğitimi & 5 & & 5 & 0,01 \\
\hline Finansal Raporlama & 4 & & 4 & 0,00 \\
\hline Finansal Kaynaklar & 4 & & 4 & 0,00 \\
\hline Entelektüel Sermaye & 2 & 2 & 4 & 0,00 \\
\hline Muhasebe Tarihi & 2 & 1 & 3 & 0,00 \\
\hline Finans Etiği & 1 & 2 & 3 & 0,00 \\
\hline Finansal Kriz & & 3 & 3 & 0,00 \\
\hline Davranışsal Finans & & 3 & 3 & 0,00 \\
\hline Elektronik Ticaret & 2 & & 2 & 0,00 \\
\hline Banka Muhasebesi & 2 & & 2 & 0,00 \\
\hline Muhasebe ve Denetim Ile IIlgili Düzenlemeler & 2 & & 2 & 0,00 \\
\hline Dış Ticaret Finansmanı & 2 & & 2 & 0,00 \\
\hline Sigorta Muhasebesi & 1 & 1 & 2 & 0,00 \\
\hline Enflasyon Muhasebesi & 1 & & 1 & 0,00 \\
\hline E-Defterler & 1 & & 1 & 0,00 \\
\hline Diğer & 3 & & 3 & 0,00 \\
\hline TOPLAM & 818 & 172 & 990 & 1,00 \\
\hline
\end{tabular}

Tablo.8'e bakıldığında, son altı yılda muhasebe ve finansman alanında yapılmış yüksek lisans ve doktora çalışmalarında denetim, uluslararası finansal raporlama standartları ve finansal uygulama çalışmalarına eğilim görülmektedir. Daha önce yapılan çalışmalarda elde edilen sonuçların aksine, özellikle muhasebe alanında eğitim gören öğrenciler denetim alanında daha çok çalışmayı tercih etmiş ve bunu uluslararası finansal raporlama standartları takip etmiştir. Bu iki önemli çalışma alanının kendi içerisindeki konu dağılımları Tablo.9 ve Tablo.10'da ayrıca açıklanmıştır.

Üzerinde yapılan çalışma sıklığı açısından tabloda dördüncü sırayı alan finansal uygulamalar kısmı incelendiğinde, finansman alanında eğitim gören akademisyen adaylarının çoğunlukla, 2013 yılına kadar İstanbul Menkul Kıymetler Borsası (iMKB) olarak adlandırılan ve günümüzde Borsa İstanbul (BIST) adı altında çalışmakta olan borsa içerisinde faaliyetlerini sürdüren şirketler üzerine yoğunlaştığı görülmüştür. Yapılan finansal uygulamaların ayrıca, ele alınan firmaların çalışma sermayeleri ve karlıııları arasındaki ilişkiler, gayrimenkul değerlemesi ve hisse senetleri gibi finansal araçların değerlemesi, Amerika'da "mortgage krizi" olarak patlak veren ve dünya ekonomisini olduğu gibi ülkemizi de 2008 yılında etkileyen küresel krizin makroekonomik açıdan ülke ekonomisine ve sektörel bazda şirketlerin bilançolarına etkileri üzerine yapıldığı görülmektedir. Finansman alanında yapılmış lisansüstü çalışmaların, son yıllarda özellikle ön plana çıktığı görülen davranışsal finans alanına da hitap ettiği gözlemlenmiştir. Davranışsal finans, yatırımcıların karar verme mekanizmalarının psikolojik açıdan ne derece etkilendiğini araştırarak, geleneksel finans anlayışında kabul edilen yatırımcıların rasyonelliği varsayımını reddeden bir yaklaşımdır (Aydoğan, 2013:33).

Araştırma kapsamına alınan lisansüstü tezlerin yoğunluk gösterdiği çalışma alanlarına bakıldığında maliyet muhasebesi ve finansal analiz alanlarının da sıklıkla kullanıldığı ayrıca görülmektedir. Maliyet muhasebesinde gerek yüksek lisans gerek doktora öğrencilerinin çoğunlukla faaliyet tabanlı maliyetleme yaklaşımı üzerinde çalıştıkları görülmekle birlikte, çalışmacılar tarafından kalite maliyetleri konusu üzerinde de durulduğu saptanmıştır. Finansal analiz kapsamında yapılan çalışmalarda, ele alınan finansal analizlerin sektörel etkileri ve finansal raporlama standartları üzerindeki etkilerine yoğunlaşıldığı görülmüştür. Muhasebe uygulamalarında ise genellikle üretim işletmelerin maliyet ve stratejik yönetim muhasebe anlayışları üzerine araştırmalar yapılmıştır. Bulgular ışığında, araştırmacılar tarafından vergi muhasebesi, dış ticaret muhasebesi, finans denetimi, işletme birleşmeleri, türev piyasalar ve özellikle araştırma kapsamına alınan süreç içerisinde 
ele alınan çalışmalarda oldukça sözü edilen transfer fiyatlandırması konularının ilgi gördüğünün söylenmesi mümkün olacaktır.

Tablo 9: Araştırma Kapsamındaki Muhasebe Tezlerinin Denetim Alanı İçerisindeki Dağılımı

\begin{tabular}{|c|c|c|c|c|}
\hline KONU & YÜKSEK LISANS & DOKTORA & TOPLAM & YÜZDE \\
\hline Bağımsız Denetim & 27 & 9 & 36 & 0,22 \\
\hline Iç Denetim & 22 & 2 & 24 & 0,15 \\
\hline iç Kontrol Sistemi & 21 & 2 & 23 & 0,14 \\
\hline Hile Denetimi & 14 & 1 & 15 & 0,09 \\
\hline Denetim Uygulamaları & 8 & 2 & 10 & 0,06 \\
\hline Denetim Meslek Mensupları & 8 & 1 & 9 & 0,05 \\
\hline Vergi Denetimi & 7 & 1 & 8 & 0,05 \\
\hline Risk Yönetimi & 6 & 1 & 7 & 0,04 \\
\hline Uluslararası Denetim Standartları & 3 & 3 & 6 & 0,04 \\
\hline Denetim Komiteleri & 5 & & 5 & 0,03 \\
\hline Kamu Denetimi & 5 & & 5 & 0,03 \\
\hline Banka Denetimi & 4 & 1 & 5 & 0,03 \\
\hline Kanit Toplama Teknikleri & 3 & & 3 & 0,02 \\
\hline Basel II - Denetim ilişkisi & 2 & 1 & 3 & 0,02 \\
\hline Denetimde Yenilikler & 2 & & 2 & 0,01 \\
\hline Muhasebe Denetimi & 2 & & 2 & 0,01 \\
\hline Faaliyet Denetimi & 1 & 1 & 2 & 0,01 \\
\hline Bilgisayarlı Denetim & 1 & & 1 & 0,00 \\
\hline Dış Denetim & 1 & & 1 & 0,00 \\
\hline TOPLAM & 142 & 25 & 167 & 1,00 \\
\hline
\end{tabular}

Araştırma kapsamına alınan lisansüstü çalışmaların konu dağıımlarını daha spesifik açıdan ele aldığımızda, ilk olarak Tablo.9'da en çok tercih edilen çalışma alanı olan denetimin kendi içerisindeki dağılımı gözlemlenmiştir. Bu tabloya göre, özellikle 2015 yılında yoğunlaşma görülen denetim alanında en çok bağımsız denetim ve iç denetim alanları üzerinde çalışılış̧tır. Yapılan çalışmalarda bağımsız denetim ve iç denetim ilişkilendirilerek ele alındığı, bununla birlikte bağımsız denetimin işletme sürekliliğine, vergi denetimine ve adli muhasebe üzerine etkilerinin incelendiği görülmektedir. Denetim alanında yapılmış en fazla lisanüstü çalışma, Okan Üniversitesi'ne aittir.

Tablo 10: Araştırma Kapsamındaki Tezlerin Standartlar İçerisindeki Dağılımı

\begin{tabular}{|c|c|c|c|c|}
\hline STANDARTLAR & YÜKSEK LISANS & DOKTORA & TOPLAM & YÜZDE \\
\hline VUK ile TFRS Arasındaki Karşılaştırmalar & 16 & 2 & 18 & 0,12 \\
\hline TMS 16 Maddi Duran Varlıklar & 14 & 1 & 15 & 0,1 \\
\hline TMS 11 inşaat Sözleşmeleri & 14 & & 14 & 0,09 \\
\hline TMS 2 Stoklar & 12 & & 12 & 0,08 \\
\hline TMS 12 Gelir Vergileri & 10 & 1 & 11 & 0,07 \\
\hline UFRS Uygulamaları & 4 & 7 & 11 & 0,07 \\
\hline KOBI-TFRS & 7 & 3 & 10 & 0,06 \\
\hline TMS 18 Hasılat & 4 & 1 & 5 & 0,03 \\
\hline TMS 23 Borçlanma Maliyetleri & 4 & & 4 & 0,03 \\
\hline UFRS Ülkeler Arası Karşılaştırma & 2 & 2 & 4 & 0,03 \\
\hline TMS 41 Tarımsal Faaliyetler & 1 & 3 & 4 & 0,03 \\
\hline TMS 20 Devlet Teşvikleri & 3 & & 3 & 0,02 \\
\hline TMS 40 Yatırım Amaçlı Gayrimenkuller & 3 & & 3 & 0,02 \\
\hline Gerçeğe Uygun Değer Muhasebesi & 3 & & 3 & 0,02 \\
\hline UFRS ve Maliyet Iilişkileri & 2 & 1 & 3 & 0,02 \\
\hline Araştırma ve Geliştirme Maliyetleri & 2 & & 2 & 0,01 \\
\hline TMS 38 Maddi Olmayan Duran Varlıklar & 2 & & 2 & 0,01 \\
\hline TMS 19 Çalışanlara Sağlanan Faydalar & 2 & & 2 & 0,01 \\
\hline TMS 7 Nakit Akım Tabloları & 2 & & 2 & 0,01 \\
\hline TFRS 3 işletme Birleşmeleri & 2 & & 2 & 0,01 \\
\hline TMS 36 Varlıklarda Değer Düşüklüğü & 2 & & 2 & 0,01 \\
\hline TMS 21 Kur Farklarının Muhasebeleştirilmesi & 2 & & 2 & 0,01 \\
\hline
\end{tabular}




\begin{tabular}{|c|c|c|c|c|}
\hline TMS 1 Finansal Tabloların Sunuluşu & 2 & & 2 & 0,01 \\
\hline UFRS 15 Müşterilerden Yapılan Sözleşmelerden Doğan Hasılatlar & 2 & & 2 & 0,01 \\
\hline TFRS 9 Finansal Araçlar & 1 & 1 & 2 & 0,01 \\
\hline TFRS 8 Faaliyet Bölümleri & 1 & 1 & 2 & 0,01 \\
\hline TMS 8 Muhasebe Politikaları & & 2 & 2 & 0,01 \\
\hline TMS 37 Karşııklar, Koşullu Borçlar ve Koşullu Varlıklar & 2 & & 2 & 0,01 \\
\hline TMS 10 Bilanço Tarihinden Sonraki Olaylar & 1 & & 1 & 0,01 \\
\hline TFRS 2 Hisse Bazlı Ödemeler & 1 & & 1 & 0,01 \\
\hline TFRS 1 Türkiye Finansal Raporlama Standartları'nın IIk Uygulaması & 1 & & 1 & 0,01 \\
\hline TMS 17 Finansal Kiralama & 1 & & 1 & 0,01 \\
\hline Dış Ticaret Işlemlerinin Muhasebeleştirilmesi & 1 & & 1 & 0,01 \\
\hline TMS 27 Konsolide Finansal Tablolar & 1 & & 1 & 0,01 \\
\hline Kavramsal Çerçeve & 1 & & 1 & 0,01 \\
\hline UFRS Farkındalığına Dair Anket Çalışmaları & 1 & & 1 & 0,01 \\
\hline TOPLAM & 129 & 25 & 154 & 1,00 \\
\hline
\end{tabular}

Dünya çapında bulunan ülkelerin faaliyetlerini analiz etme sürecinde benimseyip kullandıkları farklı muhasebe uygulamaları, uluslararası gerçekleştirilen işlemlerde sorunlar ortaya çıkardığından 1960 'lardan beri üzerinde tartışılan uluslararası muhasebe standartları, Dünya ekonomisinin globalleşmesi ve uluslararası muhasebe uygulamalarının daha da önem kazanması ile birlikte gündem konusu haline gelmiştir. Bu amaçla 1973 yılından beri bu konunun üzerinde çalışan Uluslararası Muhasebe Standartları Komitesi (IASC), Uluslararası Finansal Raporlama Standartları ile Uluslararası Muhasebe Standartları olarak hazırladığı setleri 2001 yılında yayınlamıştır. Ülkemiz de bu ortak bir muhasebe dili oluşturmak amacıyla yapılan çalışmalara 2002 yılında dahil olmuş, söz konusu standartları Türkiye Finansal Raporlama Standartları ve Türkiye Muhasebe Standartları adı altında uyarlayarak yürürlüğe sokmuştur. (Toroslu, 2010:2-5)

Ülkemizin muhasebe uygulamalarının dayandırıldığı mevcut sistem olan Vergi Usul Kanunu ile 2002'de ülkemize katılan muhasebe standartları arasında bulunan uygulama farklılıkları, muhasebe alanında çalışmalar yapan ve standartlara yatkınlığı olan akademisyen adaylarının oldukça ilgisini çekmiş ve Tablo.10'da da görüldüğü üzere standartlar üzerine çalışılan en çok konu olmuştur. Uygulama farklılıkları hususunda ele alınan standartlara bakıldığında, en fazla maddi duran varlıkların muhasebeleştirilmesi konusu ele alındığı görülmektedir. Bununla birlikte, vergi usul kanunu ile muhasebe standartları arasındaki değerleme ölçütleri farklılıkları, stokların değerleme farklılıkları ve inşaat sözleşmelerinin muhasebeleştirilmesi konularındaki uygulama farklılıklarının da incelendiği bir diğer saptanan bulgudur. Tablo genel anlamda incelendiğinde ise, TMS 16 Maddi Duran Varlıklar, TMS 2 Stoklar, TMS 11 inş̧aat Sözleşmeleri, TMS 12 Gelir Vergileri ve KOBI TFRS standartları konularının oldukça ön planda olduğu söylenebilmektedir. Standartlar üzerinde en fazla çalışma yapan üniversitenin de Marmara Üniversitesi olduğu bir diğer bulgu iken, muhasebe standartlarının bireyler tarafından daha çok yüksek lisans tezi çalışmalarında tercih edildiği saptanmıştır.

\section{SONUÇ VE ÖNERILER}

Yapılan çalışma, Yükseköğretim Kurulu Ulusal Tez Merkezi veri tabanına kayıtlı olan, muhasebe ve finansman alanına hitap eden lisansüstü çalışmaların analiz edilip yorumlandığı, son altı yılı kapsayan, ülkemiz çerçevesinde yapılmış bir araştırmadır. Çalışmanın ana amacı, lisansüstü öğrenim gören ve henüz tez çalışma alanlarını belirleme sürecinde olan bireylere, son altı yılı kapsayan bir lisansüstü çalışma alan dağılımı bilgisi sunarak, öğrencilerin karar alma süreçlerini doğru ve verimli bir şekilde değerlendirmesini sağlayabilmektir. Böylece, hem araştırmacıların araştırma yapacakları alanlardaki güncel dağıım ve yığılmaları görebilmesi, hem de bu sayede daha yaratıcı olmaları, alan içerisinde daha az bilimsel bilgiye sahip olan çalışma alanlarına yönelmeleri, böylece belirli konularda oluşan yığılmaların azaltılması hedeflenmektedir.

Araştırma bulgularının en önemlisi, araştırmacıların son altı yıl içerisinde finansman alanı yerine muhasebe alanı üzerine yoğunlaştığı olmuştur. Özellikle 2015 yılında bu iki alan arasında yapılan çalışma sayısı farkı ciddi bir oranla açılmıştır. Yüksek lisans öğrencileri muhasebe alanında daha fazla çalışma yaparken, son iki yıl içerisinde yüksek lisans öğrencileri tarafından finansman alanında yapılan çalışmaların azaldığı görülmektedir. Bunun en önemli nedeni, muhasebe alanının kendi iç dağııımının çok geniş olmasıdır. Özellikle maliyet muhasebesi alanının çok kapsamlı olması ve maliyet muhasebesi yöntemlerinin (faaliyet tabanlı maliyetleme, sipariş maliyetleme, kalite maliyetleme vb.) üretim işletmeleri üzerinde araştırılabilir ve uygulanabilir olması, bununla birlikte yönetim muhasebesi, vergi muhasebesi, kamu sektörüne ilgisi olan araştırmacılar için vergi muhasebesi, dış ticaret muhasebesi gibi alanların çalışma yapmaya çok müsait olması muhasebe alanını ön plana çıkarmaktadır. Kuşkusuz, 2002 yılından itibaren ülkemizde resmileşen ve akabinde yapılan lisansüstü çalışmalara günümüzde dahi ağırlıklı bir şekilde konu olan muhasebe standartları ile, dünya çapında gerçekleşen muhasebe skandalları ile önemi giderek artan ve muhasebe fonksiyonunun doğru ve güvenilir bilgi sağlaması için muhasebeden ayrı düşünülemeyen denetim alanının araştırmacılar tarafından oldukça ilgi gördüğü açıkça görülmektedir. 
Lisansüstü araştırmalarda, yüksek lisans çalışmalarında daha çok teorik araştırmaların, doktora çalışmalarında ise ağırlıklı olarak ampirik araştırmaların kullanıldığı görülmüştür. Bilimsel bilginin denenerek ve teyit edilerek daha çok artacağı ve denenerek ortaya çıkan sonuçların ardından yeni soru işaretleri ve yeni çalışma alanları doğuracağı düşünüldüğünde, çalışmacıların teorik çalışmalar yapmak yerine, çalışma alanlarının elverişliliği doğrultusunda ampirik araştırmalar yapması daha doğru olacaktır. Böylece araştırmacıların daha yeni, daha doğru ve daha fazla bilimsel bilgiye ulaşması sağlanacak,bu durum da çalışma alanlarına sağlayacakları katkıyı büyük oranda arttıracaktır.

Ülkemizde muhasebe ve finansman alanına son altı yıl gibi güncel bir zaman dilimi içerisinde, lisansüstü çalışmalara en çok katkı sağlayan üniversiteler Marmara Üniversitesi, Okan Üniversitesi, Gazi Üniversitesi, Sakarya Üniversitesi ve İstanbul Ticaret Üniversitesi olmuştur. Daha önce yapılmış çalışmalar ışığında, geçmiş yıllarda da benzer bulguların ortaya çıktığı bir diğer bilgidir. Özellikle Okan ve İstanbul Ticaret Üniversiteleri'nde bulunan muhasebe ve denetim çalışma alanlarını içeren bilim dallarının verimli bir şekilde faaliyet göstermesi ve Marmara Üniversitesi'nin muhasebe alanı konusunda oldukça başarılı olduğunun görülmesi, bu bilgileri kanıtlar niteliktedir.

Muhasebe alanında çalışmalar yapan araştırmacılar, son on beş yılda oldukça popülerleşen muhasebe standartları, denetim, finansal uygulamalar ve maliyet muhasebesi konularına yoğun ilgi göstermiştir. Denetim alanında gerek teorik gerek ampirik çalışmaların daha elverişli yapılabilir olması, günümüzde gittikçe gelişen bankacılık sektöründe ve borsa üzerinde faaliyet gösteren işletmelerde analiz ve uygulamasının mümkün olduğu finansal çalışmalar ve üretim işletmelerinin temel taşı olan maliyet muhasebesinin belirli bir işletme, bir il veya bir sanayi bölgesi seçilmek suretiyle üzerinde araştırma ve analiz yapılmasının mümkün olması, bu alanları araştırmacılar açısından daha cazip kılmıştır. Bahsedilen bu çalışma alanlarının, analiz kapsamına alınan çalışmaların \%55 gibi bir dilimine sahip olması da, bu bilgileri kanıtlar niteliktedir.

Son yıllarda çalışma yığıımalarının görüldüğü muhasebe standartları konusu, araştırmacılar tarafından TMS 16 Maddi Duran Varlıklar, TMS 2 Stoklar, TMS 11 İnşaat Sözleşmeleri, TMS 12 Gelir Vergileri çoğunlukla ele alınmak suretiyle incelenmiştir. Bununla birlikte, analiz ve yoruma oldukça elverişli olan muhasebe standartlarının ülkemiz muhasebe sistemi Vergi Usul Kanunu ile arasındaki uygulama farklılıklarının araştırılması, yapılan standart konulu çalışmalarda öne çıkan bir diğer araştırma alanıdır. Vergi Usul Kanunu ile muhasebe standartları arasındaki uygulama farkları kadar, muhasebe meslek mensuplarının gittikçe önemi artan ve artık üzerinde bilgi sahibi olunmamasının kabul görmeyeceği muhasebe standartlarını ne derece doğru anladıkları ve ne derece doğru uyguladıklarının araştırılması da oldukça önem taşımaktadır. Bu nedenle araştırmacıların son altı yılda neredeyse üzerinde hiç çalışılmayan bu konu üzerine yoğunlaşması, muhasebe standartlarının ülkemizdeki uygulanabilirliğini daha çok geliştirecek, verimini arttıracaktır.

Muhasebe ve finansman alanında yapılan çalışmaların analiz edilerek incelenmesinin, lisansüstü çalışmalar yapmakta olan araştırmacılar kadar, bu alanda bilimsel bilgi ihtiyacı duyan ve bilimsel bilgi üretme isteğinde olan diğer tüm bireylere de yol göstereceği bir gerçektir. Bu nedenle bu araştırmanın ortalama on yılda bir güncellenerek ortaya konulması, muhasebe ve finansman alanlarında yığılma yaşanan ve kısmen kenarda bırakılan çalışma alanlarını açığa çıkartacağı ve akademik çalışmalar yapan araştırmacılar ile onların liderliğini üstlenen akademik danışmanlara ışık tutacağı düşünülmektedir. Muhasebe ve finansman alanına ilgi duyan araştırmacıların, Türkiye'de bu alanlarda yapılmış lisansüstü çalışmalar kadar ilgili alanlarda yazılmış bilimsel makaleleri de inceleyerek makaleler üzerindeki konu dağılım ve ortaya konulan genel kanıları değerlendirmesinin, muhasebe ve finansman alanına çok daha fazla bilimsel bilgi katacağı düşünülmektedir. Böylece muhasebe ve finans alanlarına ilgili olan kişiler ve lisansüstü çalışmalar yapmakta olan bireylere farkındalık kazandırmakla birlikte bireylerin bakış açılarının genişlemesi sağlanabilecektir.

\section{KAYNAKÇA}

Akyüz, F., Yeşil, T. (2017), "TFRS Açısından Muhasebe Meslek Mensuplarına Yönelik Yapılmış Olan Akademik Çalışmaların Değerlendirilmesi", Optimum Ekonomi ve Yönetim Bilimleri Dergisi, Sayı 4:77-95.

Alkan, G. (2014), "Türkiye'de Muhasebe Alanında Yapılan Lisansüstü Tez Çalışmaları Üzerine Bir Araştırma (1984-2012)", Muhasebe ve Finansman Dergisi, Sayı 64:41-52.

Armutlu, C., Arı, Güler S. (2010), "Yönetim Modalarının Yüksek Lisans ve Doktora Tezlerine Yansımaları: Bibliyometrik Bir Analiz", ODTÜ Gelişme Dergisi, Sayı 37: 1-23.

Aydoğan, N. (2013), "Zıtlık Yatırım Stratejisinin Davranışsal Finans i̇le Değerlendirilmesi-Borsa İstanbul (BisT) Üzerine Bỉr Uygulama, (Yayınlanmamış Yüksek Lisans Tezi), Uludağ Üniversitesi Sosyal Bilimler Enstitüsü, Bursa. 
Benligiray, S. (2012), "Araştırmacıların Bankacılık Alanına Bilimsel Katkıları: Bankacılık Konusunda Yapılan Lisansüstü Tezlere ilişkin Bir Araştırma", Süleyman Demirel Üniversitesi Vizyoner Dergisi, Cilt 3, Sayı 6: 26-46.

Bozyiğit, S., Yaşa, E. (2012), "Araştırmacıların Pazarlama Alanına Bilimsel Katkıları: Pazarlama Konusunda Yapılan Lisansüstü Tezlere İlişkin Bir Araştırma", 17. Ulusal Pazarlama Kongresi Bildiri Kitabı (56-76), Balıkesir.

Elitaş, C., Elitaş, Bilge L. (2016), "Türkiye'de Muhasebe Tarihi Çalışmalarına İlişkin Birikim: 2005-2015 Dönemini Kapsayan Bir İnceleme", İstanbul Üniversitesi İşletme Fakültesi Dergisi, Vol.45, Özel Sayı: 110-117.

Güngörmüş, Ali H. (2016), " Türkiye'de Muhasebe Standartlarına Yönelik Yazılan Yüksek Lisans Ve Doktora Tez Çalışmaları Üzerine Bir Araştırma", Pamukkale Üniversitesi Sosyal Bilimler Enstitüsü Dergisi, Sayı 25: 347-362.

Solmaz, E., Gökçearslan, Ş. (2016), "Mobil Öğrenme:Lisansüstü Tezlere Yönelik bir İçerik Analizi Çalışması", 10. Uluslararası Bilgisayar ve Öğretim Teknolojileri Sempozyumu (554-561), Rize.

Tekin, Ömer A. (2016), "Türkiye'deki Lisansüstü Turizm Tezlerinde Odaklanılan Konular: 1984-2015",Uluslararası Alanya İşletme Fakültesi Dergisi, Sayı:2: 175-187.

Toroslu, Vefa M. (2010), "Türkiye Muhasebe Standartlarında Stok - Maliyet iliş̧kisi: TMS 2 Stoklar, TMS 23 Borçlanma Maliyetleri", Yayımlanmış Yüksek Lisans Tezi, Okan Üniversitesi Sosyal Bilimler Enstitüsü, İstanbul.

Yereli, A., Kayalı, C., Özdoğan, B., Gacar, A. ve Ata, Fatma İ. (2010), "Uluslararası Muhasebe Eğitimi Literatür Taraması", Ege Akademik Bakış, Sayı 3: 885-910. 